\title{
A Review of Existing Models and Methods to Estimate Employment Effects of Pollution Control Policies
}
R. F. Darwin
R. J. Nesse

February 1988

Prepared for

the U.S. Environmental Protection Agency

under a Related Services Agreement

with the U.S. Department of Energy

under Contract DE-AC06-76RLO 1830

Pacific Northwest Laboratory

Operated for the U.S. Department of Energy

by Battelle Memorial Institute 
Although the research described in this article has been funded wholly or in part by the United States Environmental Protection Agency (EPA), it has not been subjected to EPA review and therefore does not necessarily reflect the views of EPA and no official endorsement should be inferred.

\title{
DISCLAIMER
}

This report was prepared as an account of work sponsored by an agency of the United States Government. Neither the United States Government nor any agency thereof, nor Battelle Memorial Institute, nor any or their employees, makes any warranty, expressed or implied, or assumes any legal liability or responsibility for the accuracy, completeness, or usefulness of any information, apparatus, product, or process disclosed, or represents that its use would not infringe privately owned rights. Reference herein to any specific commercial product, process, or service by trade name, trademark, manufacturer, or otherwise does not necessarily constitute or imply its endorsement, recommendation, or favoring by the United States Government or any agency thereof, or Battelle Memorial Institute. The views and opinions of authors expressed herein do not necessarily state or reflect those of the United States Government or any agency thereof, or Battelle Memorial Institute.

\author{
PACIFIC NORTHWEST LABORATORY \\ operated by \\ BATTELLE MEMORIAL INSTITUTE \\ for the \\ UNITED STATES DEPARTMENT OF ENERGY \\ under Contract DE-AC06-76RLO 1830
}

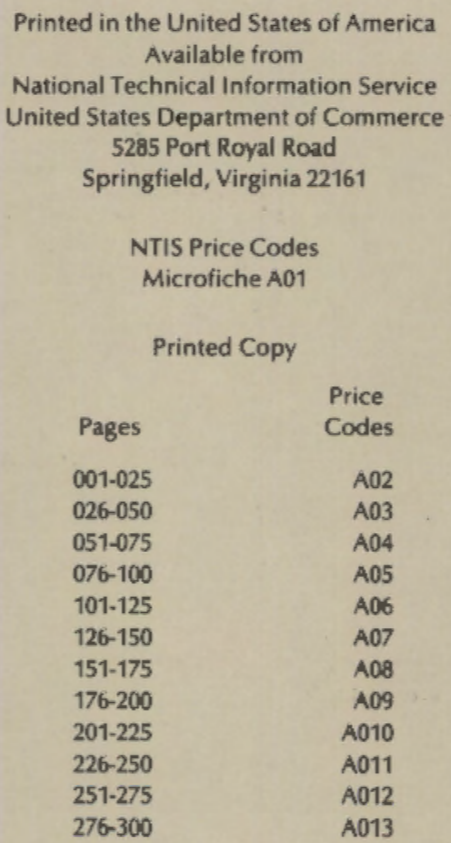


A REVIEW OF EXISTING MODELS AND METHODS TO ESTIMATE EMPLOYMENT EFFECTS OF POLLUTION CONTROL POLICIES
R. F. Darwin
R. J. Nesse

February 1988

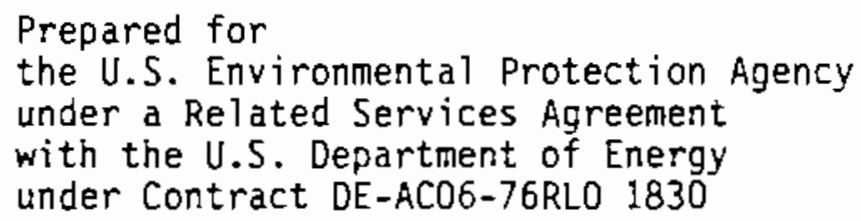

Pacific Northwest Laboratory Richland, Washington 99352 


\section{SUMMARY}

This working paper was prepared by Pacific Northwest Laboratory (PNL) for the Office of Program Development within the U.S. Environmental Protection Agency's (EPA) Office of the Assistant Administrator for Air and Radiation. The purpose of this paper is to provide information about existing models and methods used to estimate coal mining employment impacts of pollution control policies. The EPA is currently assessing the consequences of various alternative policies to reduce air pollution. One important potential consequence of these policies is that coal mining employment may decline or shift from low-sulfur to high-sulfur coal producing regions. The EPA requires models that can estimate the magnitude and cost of these employment changes at the local level.

This paper contains descriptions and evaluations of three models and methods currently used to estimate the size and cost of coal mining employment changes. The first model reviewed is the Coal and Electric Utilities Model (CEUM), a well established, general purpose model that has been used by the EPA and other groups to simulate air pollution control policies. The second model reviewed is the Advanced Utility Simulation Model (AUSM), which was developed for the EPA specifically to analyze the impacts of air pollution control policies. Finally, the methodology used by Arthur D. Little, Inc. to estimate the costs of alternative air pollution control policies for the Consolidated coal Company is discussed. These descriptions and evaluations are based on information obtained from published reports and from draft documentation of the models provided by the EPA.

The major findings are listed below:

1. All three models and methods provide estimates of coal mining employment impacts. Only the ADL methodology, however, provides state-level estimates of employment impacts that would indirectly occur in those industries that provide goods and services to the coal mining industry (indirect effects). Similarly only the ADL study estimates the employment impacts that employment changes in both the coal mining and its supporting industries would induce in industries providing final goods and services to households (induced effects). 
2. The reliability of coal mining employment estimates rests on the reliability of (a) coal production estimates and (b) the conversion factors linking coal production to employment. The coal production estimates generated by the CEUM and the AUSM or used in the ADL study may have problems. For example, neither the CEUM nor the AUSM's coal production estimates account for changing migration patterns resulting from the reduced employment in air pollution control scenarios. Not enough information is readily available to determine whether these or other problems exist with ADL's coal production estimates. We can not tell how important these problems might be for analyses of air pollution control policies at the local level.

3. Production in industries other than coal production also might be directly affected by air pollution control policies. Production changes in the transportation and utility industries, for example, also are likely to affect employment in coal producing regions.

4. Additional research might focus on:

- Alternative methods of incorporating employment impacts in those industries that provide final goods and services to households (induced effects) into analyses of air pollution control policies;

- Determining the importance of the various problems associated with methods currently used to model coal production;

- Evaluating ways to estimate employment effects caused by production changes in the transportation and utility industries;

- Reviewing methods to also include nonemployment impacts (for example, tax revenues, transfer payments, and housing impacts) caused by changes in coal production;

- Analyzing the state level employment effects of alternative ways of meeting a state-level emission target;

- Analyzing ways of compensating unemployed coal miners or mitigating the Joses of their unemployment, and

- Estimating migration effects of unemployed coal miners through regional employment models or case studies. 


\section{CONTENTS}

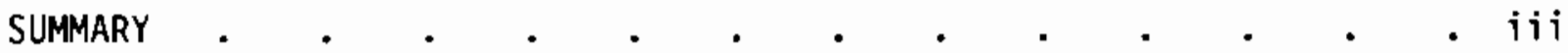

1.0 INTRODUCTION

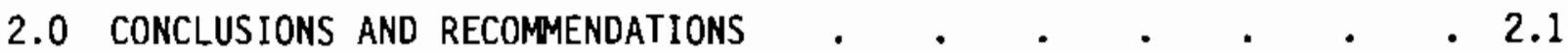

3.0 THE COAL AND ELECTRIC UTILITIES MODEL $\quad . \quad \cdot \quad \cdot \quad \cdot \quad \cdot \quad \cdot 3.1$

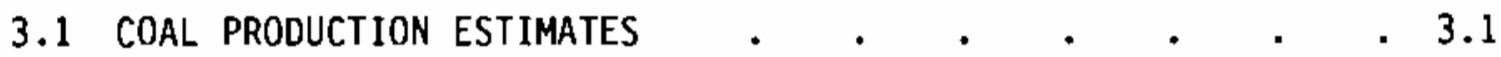

3.2 COAL MINING EMPLOYMENT: ESTIMATES AND IMPACTS $\cdot . \cdot 3.3$

3.3 EVALUATION $•$.

4.0 THE ADVANCED UTILITY SIMULATION MODEL . . . • . • • 4.1

4.1 COAL PRODUCTION ESTIMATES.$\quad$.

4.2 COAL MINING EMPLOYMENT: ESTIMATES AND IMPACTS $\cdot \bullet^{\cdot} \cdot 4.8$

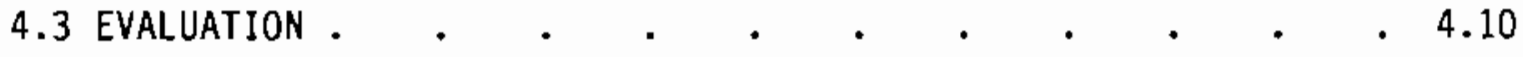

5.0 ARTHUR D. LITTLE INC. CONSOLIDATED COAL STUDY • • • • $\quad 5.1$

5.1 COAL MINING EMPLOYMENT: ESTIMATES AND IMPACTS $\cdot{ }^{*} \cdot 5.1$

5.2 EVALUATION $. \quad . \quad . \quad . \quad . \quad . \quad . \quad . \quad . \quad . \quad .5 .3$

6.0 PROPOSED FUTURE RESEARCH . $\quad . \quad . \quad . \quad . \quad . \quad . \quad . \quad .6 .1$

6.1 SENSITIVITY ANALYSIS OF THE CEUM AND AUSM'S COAL PRODUCTION ESTIMATES • $\cdot$ • $\cdot$ •

6.2 ESTIMATING STATE-LEVEL EMPLOYMENT EFFECTS CAUSED BY CHANGES IN COAL PRODUCTION

6.3 DESCRIPTION AND EVALUATION OF METHODS USED TO DETERMINE EMPLOYMENT EFFECTS CAUSED BY OUTPUT CHANGES IN THE TRANSPORTATION AND ELECTRIC UTILITY INDUSTRIES • $\cdot \cdot 6.3$

6.4 ESTIMATING THE TOTAL STATE-LEVEL IMPACTS CAUSED BY CHANGES IN COAL PRODUCTION $\cdot$.

6.5 ASSESSING ALTERNATIVE COAL MINER COMPENSATION POLICIES . $\quad 6.4$ REFERENCES $\cdot$ •

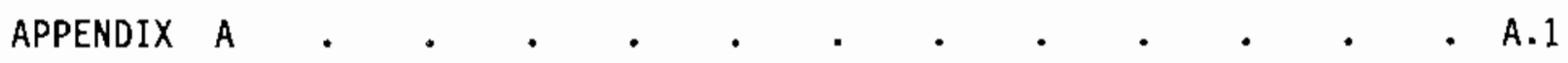

\section{FIGURES}

4.1 Major Information Flows Between the AUSM's Modules. . . . 4.3 



\subsection{INTRODUCTION}

The U.S. Environmental Protection Agency (EPA) is currently assessing the consequences of various policies that might be used to reduce air pollution. One of the issues discussed in these assessments is whether or not sulfur dioxide $\left(\mathrm{SO}_{2}\right)$ control policies should restrict switching from highsulfur to low-sulfur coal, e.g. mandate the use of scrubbers. This issue is important because the size and location of the employment effects that these two policy alternatives might have within the coal mining industry are different. Switching from high-sulfur to low-sulfur coal, for example, would cause employment opportunities in coal mining to shift from high-sulfur to low-sulfur coal regions. Requiring the use of scrubbers would cushion these adverse employment effects within high-sulfur coal regions. Because policy analysts are generally sensitive to large, negative, regional impacts, reliable information is needed about the regional employment changes caused by alternative pollution control policies.

The total change in regional employment resulting from changes in coal production can be divided into three components: 1) changes in employment in the coal industry itself (direct effects); 2) changes in employment for firms that supply the coal industry (indirect effects), and 3) changes in employment resulting from changes in the purchases of direct and indirect workers (induced effects). For example, if a specific pollution control policy caused the shut-down of several ohio mines, the direct effects are the changes in local coal mining employment, the indirect effects are the changes in employment for local firms that supply equipment to the coal mine companies, and the induced effects are the changes in employment in local grocery stores due to the reduced business from the unemployed miners. Including indirect and induced effects is important since most analysis of regional employment impacts indicate that the indirect and induced employment effects may be as large or larger than the direct effects.

The first objective of this report is to describe and evaluate models and methods currently used to predict employment impacts that various air pollution control policies might induce in coal mining areas. The models and methods described include the Coal and Electric Utilities Model (CEUM), the 
Advanced Utility Simulation Model (AUSM), and the methods used by Arthur D. Little, Inc. (ADL) to estimate the costs of alternative air pollution control policies for the Consolidation Coal Company. The evaluation focuses on how the models and methods estimate the direct effects of pollution control policies on employment in the coal mining industry and how these changes in coal mining employment are used to estimate indirect and induced employment effects. Direct, indirect, and induced employment changes caused by pollution control policies through other industries, i.e. transportation, construction, etc., are not evaluated. The second objective of this report is to determine what research might be undertaken to verify or improve estimates of employment impacts induced by changing levels of coal production.

The rest of this paper is divided into five sections. Chapter 2.0 contains the report's conclusions and recommendations. Chapter 3.0 through Chapter 5.0 contain descriptions and evaluations of how coal mining employment estimates are generated by the CEUM, the AUSM, and the ADL methodology, respectively. In Chapter 6.0 , proposals for future research are outlined. 


\subsection{CONCLUSIONS ANO RECOMMENDATIONS}

The contents of this report indicate that current modeling methodologies, i.e. the CEUM, the AUSM, and the ADL Study, provide an incomplete picture of the unemployment effects that might be induced by changes in coal production. Our conclusions regarding the limitations of these models are outlined below:

- Although all of the methodologies provide estimates of direct employment effects at the state level, only one, the CEUM, currently provides estimates of direct employment effects at the local or county level.

- Indirect employment effects are estimated by both the ASUM and the ADL study. Only the AOL methodology, however, yields estimates of indirect employment effects at the state and county level. The AUSM provides estimates of indirect employment effects at the national level.

- Induced employment effects are estimated only in the ADL Study. The ADL methodology provides estimates of induced employment effects at the state and county level.

The reliability of coal mining employment estimates, however, rests on the reliability of (a) coal production estimates and (b) the conversion factors linking coal production to employment. The coal production estimates generated by the CEUM and the AUSM or used in the ADL study may not be without problems. Neither the CEUM or the AUSM's coal production estimates, for example, account for changing migration patterns in air pollution control scenarios. Not enough information is readily available to determine whether these or other problems exist with ADL's coal production estimates. It is not known how important these problems might be for analyses of air pollution control policies at the local level.

Finaliy, although this study focused specifically on the employment effects that might be caused by changes in coal production, policy-induced output changes in other industries also might affect employment in coal mining regions. Both the AUSM and the ADL Study, for example, provide estimates of employment effects caused by output changes in the transportation and utility industries as well as in the coal mining industry. The CEUM provides estimates of employment effects caused by output changes in the transportation industry. 
Given the results of this evaluation, we recommend that additional research focus on:

1. Alternative methods of incorporating indirect and induced employment effects into analyses of air pollution control policies at the state and county level.

2. Determining the importance of current modeling problems associated with estimates of direct and indirect employment effects caused by changes in coal production.

3. Evaluating ways to estimate employment effects caused by production changes in the transportation and utility industries.

4. Reviewing methods and procedures for extending the scope of policy analyses by estimating the total state-level impacts (for example, housing, demographic, local tax revenue) caused by changes in coal production.

5. Analyzing the state-level employment effects of alternative ways of meeting a state emission target.

6. Analyzing ways of compensating unemployed coal miners or mitigating the impacts of their unemployment.

7. Estimating migration effects of unemployed coal miners through regional employment models or case studies. 


\subsection{THE COAL AND ELECTRIC UTILITIES MODEL}

The Coal and Electric Utilities Model (CEUM) is a large linear program model developed and owned by ICF Incorporated (ICF). The CEUM simulates the behavior of the U.S. coal market and has been used to analyze a number of issues affecting coal production and electric power generation. These issues include the regional development of coal resources, price changes of alternative fuels, the adaptation of new technologies, and the implementation of pollution control policies. In the last instance, for example, the CEUM (or its precursor, the National Coal Model) has been used to asses the impacts of various policies of reducing $\mathrm{SO}_{2}$ emissions for the Environmental Protection Agency, the Department of Energy, the Edison Electric Institute, the National Wildlife Federation, and the Clean Air Coalition.

This chapter is divided into three sections. Section 3.1 contains a brief description of how the CEUM generates coal production estimates. These coal production estimates provide the basis for estimates of coal mining employment. In Section 3.2 the CEUM's linkages between coal production and coal mining employment are outlined. The CEUM's estimates of coal mining employment are evaluated in Section 3.3. The sources of information used to compile this section include publications from previous uses of the model, i.e. U.S. Office of Technology Assessment (1984), ICF Incorporated (1985), Stauffer (1985); ICF Incorporated (1986), and the U.S. Congressional Budget Office (1986); draft documentation of the CEUM provided by the EPA; $(a)$ and telephone conversations with Mr. Judah Rose, an employee of ICF.

\subsection{COAL PRODUCTION ESTIMATES}

The CEUM estimates coal production as part of an equilibrium solution that balances the production of coal from 40 supply regions with the consumption of coal in 47 supply regions. The solution of the model minimizes the total cost of coal mining, coal transportation, and electricity generation

(a) ICF Incorporated. n.d. Executive Summary: ICF's Coal and Electric Utilities Model. Draft. $18 \mathrm{pp}$. and ICF Incorporated. 1986. Summary Overview: ICF's Integrated Coal and Electric Utility System of Models. Draft. 78 pp. 
required to satisfy given regional levels of electricity demand and non-utility demands for coal. Coal production forecasts are given by region and coal-type.

Most demand regions correspond to individual states. Some states, however, are divided into two or more demand regions while other states are combined to form a single demand region. Coal demand within each region is further disaggregated by consuming sector--a utility sector and a non-utility sector. The non-utility sector is in turn broken down into domestic coking, industrial/retail, steam export, metallurgical export, and synthetic fuels subsectors. In the utility sector, the CEUM minimizes the cost of generating an exogenously determined amount of electricity within each region. In the non-utility sector, the model minimizes the cost of an exogenously determined quantity of coal given coal-type requirements and projected levels of subsector output.

The CEUM's 40 coal supply regions are scattered across the contiguous 48 states, i.e. the "lower 48," and Alaska. None of the coal supply regions crosses a state boundary or the boundary of a U.S. Department of Interior leasing region. Several states contain more than one supply region to account for strong intrastate differences caused by the location of coal fields or transportation infrastructures. Further disaggregation is obtained by distinquishing between the different coal-types found within a given supply region. In the CEUM coal is classified into 50 possible types--49 for bituminous coals (seven British themal unit (Btu)/volatility levels combined with seven sulfur content levels) and one for anthracite. A dozen or more coal-types may be assigned to one supply region.

Supply curves in the CEUM are developed for each coal-type within a region using coal reserve data and engineering-based mine-costing procedures. The supply curves are formulated as "step" functions where each step represents an existing or potential mine type. The length of each step represents the amount of coal available from that type of mine. The height of the step represents the minimum price that coal producers would accept given a nomal rate of return. The minimum price includes charges for coal preparation, i.e. cleaning, sulfur reduction, etc., when applicable. The model contains about 200 supply curves, each representing a specific coal-type in one of the 40 supply regions. 
The calculation of minimum prices for a mine-type is performed by ICF's coal mine costing programs, i.e. the Reserve Allocation and Mine Costing Model. The mine costing programs are based on engineering and financial principles. Numerous mine-types can be represented. For underground mines, characteristics can include seam thickness, depth of cover, number of developable production sections, and type of mining equipment, i.e. longwall versus continuous miners. For surface mines, mine-types can vary according to overburden ratio, mine size, and mining method, i.e. truck and shovel, dragline, or contour mining. Assumptions about state and federal taxes, required return on investment, union affiliation, productivity trends, and other factors also can be controlled by the user.

A complex transportation network links the coal supply regions with the demand regions. This network is actually a collection of smaller networks because each of the demand sectors has its own unique transportation characteristics and is individually modeled. Thus, the transportation networks vary by routes, modes, costs, and location of origin and destination points within the regions. Transportation costs and distances are estimated for unit trains, river barges, Great Lakes steam vessels, intercoastal barges, ocean vessels, and trucks. Transshipment charges for going from one mode of transportation to another are also included where appropriate in the cost estimates.

\subsection{COAL MINING EMPLOYMENT: ESTIMATES AND IMPACTS}

Coal mining employment forecasts published by ICF are developed from information contained (in part or in whole) within the CEUM. Mr. Judah Rose, a staff member of ICF, stated that employment estimates in the CEUM are derived simultaneously with coal production estimates (telephone conversation on October $22,1986)$. Both the coal production and employment estimates are based on mine-type, regional, and productivity factors used to derive the model's supply functions. Mines, for example, are classified into two types--deep and surface. Deep mines are further classified by coal seam thickness and mining practices. Surface mines are classified by size and overburden ratios. Union mines are also separated from non-union mines. ICF's estimates of the direct effects of coal production changes on coal mining employment, therefore, are based on 
ADDENDUM

(This page replaces page 3.4 of the report)

geographic units smaller than the mode]'s supply regions and, like the CEUM's coal production estimates, are sensitive to intraregional differences in the coal mining industry.

Only a few CEUM-based studies have attempted to estimate indirect or induced effects. The 1984 office of Technology Assessment study, for example, uses employment estimates combined with coal miner income data to estimate "direct" income effects. These direct income effects are then combined with income multipliers to obtain "very rough" approximations of the regional economic activity dependent on coal mining. The CEUM itself does not generate estimates of indirect or induced employment effects caused by changes in coal production.

\subsection{EVALUATION}

The major strength of the CEUM is its ability to generate direct coal mining employment effects at the local, i.e. coal supply region, level. Because the CEUM's coal supply regions are smaller than states, the geographic units of measure are groups of counties. Also, because mine costing procedures link coal production with employment in the CEUM, estimates of direct coal mining employment effects take local differences in mining conditions into account.

A source of potential concern is whether the coal production estimates are systematically biased, and, if so, whether this bias is large enough to cause problems. Systematically biased estimates of coal production are introduced on the demand side of the CEUM. In the utility sector, the quantities of electricity demanded are exogenously determined or fixed for each analysis. In the non-utility sector, the quantities of coal demanded are fixed. Fixing the quantities of electricity and coal demanded limits the CEUM's flexibility in two ways. First, the CEUM can not simulate consumer 
responses to changes in the price of electricity or coal in the utility and non-utility sectors respectively. For example, if the price of coal increased, the quantity of coal demanded by the non-utility sector would be expected to decrease all else being equal. In the utility sector the situation is more complex because the CEUM partially simulates the response of electric utilities to changes in coal prices by allowing utilities to substitute alternative fuels such as oil in the production of electricity. Increases in coal prices, however, would still cause the price of electricity to increase. The quantity of electricity demanded would then be expected to decrease, which would, in turn, be translated into a decrease in the quantity of all fuels (including coal) demanded.

Second, fixing electricity and coal quantities limits the CEUM's flexibility by precluding regional changes in demand through migration. For example, implementation of pollution control policies which allow extensive switching from high-sulfur to low-sulfur coal will cause coal production in low-sulfur coal regions to increase. This increase in coal production (which is simulated by the CEUM) could also result in the establishment of new communities in low-sulfur coal regions. All else being equal, however, a large influx of new inhabitants would cause the demand for electricity in those regions to increase as well. This increase in electricity demand in turn would stimulate an additional increase in the quantity of coal demanded and produced. This additional increase in coal production is not taken into account in the studies listed above.

In high-sulfur coal regions, on the other hand, just the opposite could occur. As coal production decreased in high-sulfur coal regions, substantial portions of the population might migrate to other regions. Hence the demand for electricity in high-sulfur coal regions could decrease. This decrease in demand in turn would stimulate an additional decrease in the quantity of coal demanded and produced within the region.

This demand inflexibility means that care should be taken when evaluating results generated by the CEUM in assessments of pollution control policies. Relative to a base case, for example, the CEUM will tend to overestimate total U.S. coal production (and coal mining employment) when simulating a policy which reduces $\mathrm{SO}_{2}$ emissions because it ignores the impacts of increasing the 
price of coal. The magnitude of the overestimation is probably greater when more stringent policies are simulated. That is, more stringent policies would induce higher electricity and coal prices which in turn would cause lower levels of total U.S. coal production.

The CEUM's demand inflexibility has implications at the regional level as well. In low-sulfur coal regions, for example, higher coal prices would reduce the quantities of coal demanded by local inhabitants whereas an influx of new inhabitants would increase the quantities of coal demanded. These two effects tend to cancel each other. Relative to a base case, then, the CEUM may either overestimate or underestimate coal production and coal mining employment in low-sulfur coal regions when simulating $\mathrm{SO}_{2}$ reducing policies. In high-sulfur coal regions, however, these two effects move in the same direction. Both higher electricity prices and an outmigration of inhabitants would decrease the quantities of coal demanded. Thus, relative to a base case, the CEUM will overestimate coal mining employment in high-sulfur coal regions.

This demand inflexibility may not be very important, however, especially if the consumption of electricity and coal is relatively insensitive to changing prices or if the levels of immigration and emigration are small. Also, some improvement in coal production estimates can be obtained by introducing some flexibility on the demand side of the CEUM itself. Mr. Judah Rose stated that the CEUM can adjust the quantities of electricity demanded iteratively by incorporating price elasticities of electricity demand into the modeling process. Similarly, by incorporating income elasticities of electricity demand into the modeling process, the impacts of migration-induced impacts on the quantities of electricity demanded could captured. 


\subsection{THE ADVANCED UTILITY SIMULATION MODEL}

The Advanced Utility Simulation Model (AUSM) was developed for the U.S. Environmental Protection Agency (EPA) by researchers at the University of Illinois at Urbana-Champaign, Cornell University, and Carnegie-Mellon University. The researchers performing the work were known collectively as the University Research Group on Energy (URGE). The AUSM was explicitly designed to analyze the impacts of alternative pollution control policies on the U.S. electric utility sector.

Work on the AUSM began in September 1980. Initially efforts were directed at the development of one-company, annual models that explicitly capture interactions between changing construction or operating costs, electricity prices, and electricity demand. Next, the utility sector was linked with the supply of coal on a state-by-state basis. This state-level model was completed, tested, and implemented in the public domain by November 1984. Meanwhile a national-level postprocessor, the Energy and Employment Impacts Module (EEIM), was constructed to use state-level AUSM output in determining the energy, employment and other economics impacts of various scenarios.

The remainder of this chapter is divided into three sections. Section 4.1 focuses on how the state-level AUSM determines levels of coal production. Section 4.2 describes how coal production levels in turn are used by the EEIM to derive coal mining employment effects. Section 4.3 contains an evaluation of the AUSM's estimates of coal mining employment. The sources of information used to compile this section consisted of draft documentation of the AUSM provided by the EPA. (a)

(a) Hannon, Bruce, Randall W. Jackson, and Douglas Kennedy. 1983. The Energy and Employment Module of the Advanced Utility Simmulation Model. Draft. Urbana, 1L: URGE Project Office, University of Illinois at Urbana-Champaign. $61 \mathrm{pp}$, URGE Project Office. 1983. The State-Level Advanced Utility Simulation Model: Analytical Documentation. Draft. Urbana, IL: University of Illinois at Urbana-Champaign. 372 pp., and Stukel, James J. 1984. Chapter 1: 1ntroduction and Overview of The State-Level Advanced Utility Simulation Model: Analytical Documentation. Draft. Urbana, IL: URGE Project2 0ffice, University of Illinois at Urbana-Champaign. 23 pp. 


\subsection{COAL PRODUCTION ESTIMATES}

The core of the AUSM system consists of a set of modules that simulates the utility sector on a state-by-state basis. The core modules are based on the following analyses; 1) electricity demand, 2) capacity planning, 3) pollution control technology, 4) dispatching, and 5) electric utility finance. These modules are run in sequence and the completion of a run or "pass" through the modules represents one year for a given state. Forecasts two or more years into the future require two or more passes. The model operates in an annually recursive fashion in that, except for the initial year, some output from previous passes is used as input in subsequent passes. Once the required number of passes for one state is completed, the modules are run for other states, each in succession. All of the 48 contiguous states, i.e. all states except Alaska and Hawaii, may be included in any one simulation. The major information flows between the core modules is shown in Figure 4.1.

The demand model is the first module run during a pass and completes five major tasks. First, information about finances is used to set the electricity rates for the current year. (a) Second, the rates are combined with externally provided information about the prices of primary fuels, other economic conditions, and the region's population to predict the quantities of electricity and primary fuels demanded in four sectors, i.e. residential, commercial, industrial, and transportation. Third, the sales of electricity to these four sectors are aggregated and modified to account for transmission, distribution, and other losses and for interstate transfer. Additional load characteristics, such as the system load factor, are specified so that the information passed to the dispatching module reflects generation and peak load net of transfers. Fourth, a projection is made of the system load 10 years ahead of the current year. This projection is used in the planning module to develop a construction plan for new generating facilities. Fifth, total revenues received during the current year and the net cost of interstate transfers are derived and passed to the finance module.

(a) In the first pass though the demand module, finance information is supplied from outside the AUSM. In subsequent passes, finance information is supplied by the finance module. 


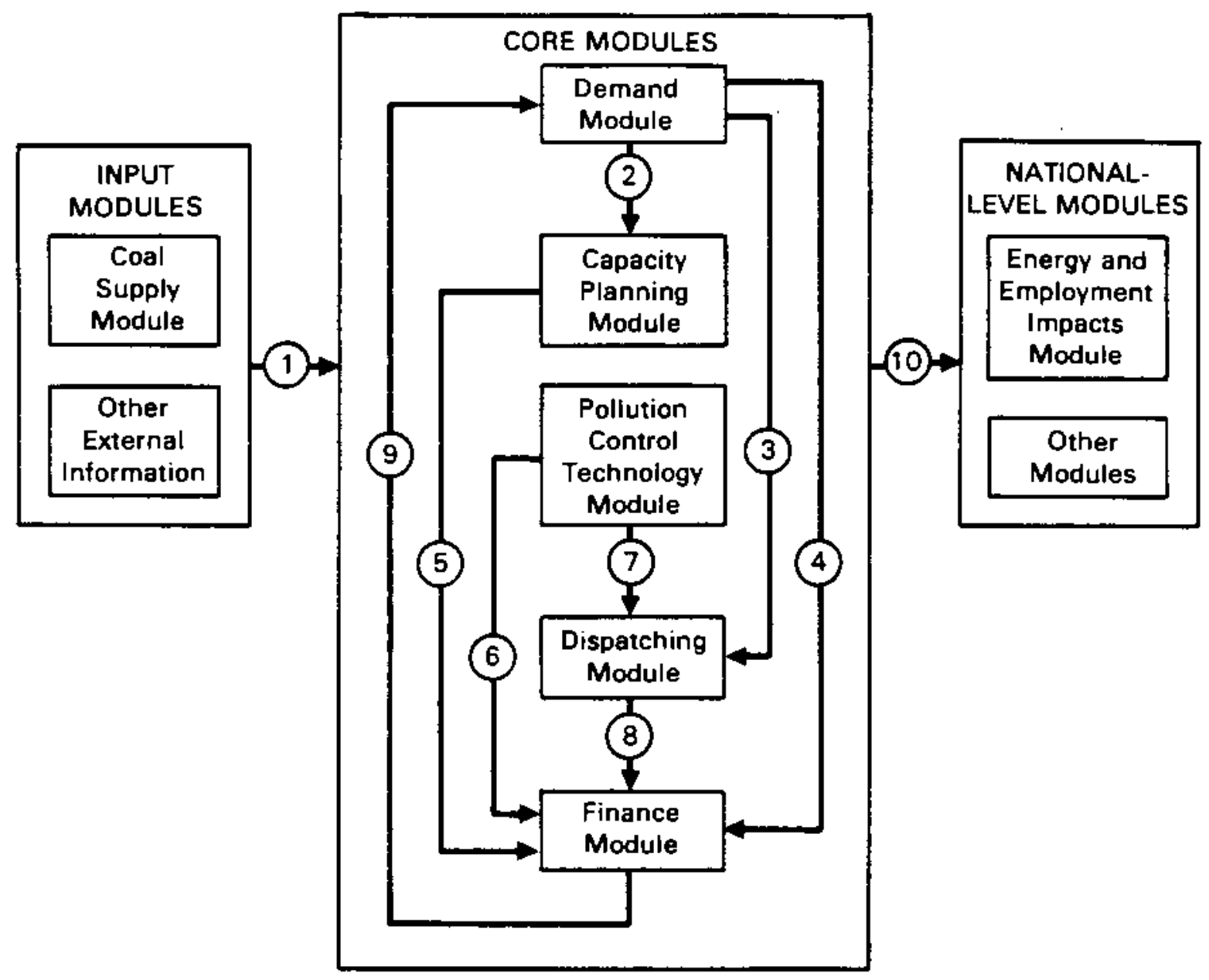

(1) External information; i.e. fuel prices, population data, etc.

(2) Projected levels of future demand

(3) Level of energy and peak load demanded in the current year net of interstate transfer

(4) Total revenue received and the net cost of interstate transfer in the current year

(4) Construction costs

(6) Pollution control investment costs

(7) Fuel choice at generating plants

(8) Operating costs

(9) Total revenue requirements for the next year

(10) Levels of demand for electricity and other fuels

Fiqure 4.1. Major Information Flows Between the AUSM's Modules 
Energy demand in the demand module is disaggregated into five sectors: residential, commercial, industrial, transportation, and electric utilities. Econometrically-based demand equations derived from data between 1967 and 1979 are used to calculate the quantities of electricity and primary fuels, i.e. natural gas, oil, and coal, demanded by the first three sectors. Except for the intercept terms, the same set of parameter estimates is used for all states. The first three sectors account for almost all of the final sales of electricity. The demand for electricity in the transportation sector is relatively small and is treated as a fixed proportion of the quantity demanded in the commercial sector. The demand equations for these four sectors are formulated to account for substitution possibilities between electricity and the other primary fuels. The "use" of electricity by electric utilities accounts for all of the difference between the quantity of electricity generated and final sales. This use is composed primarily of transmission and distribution line losses and interstate transfers. Coal is included as a primary fuel only in an aggregate industrial sector. The amount of coal used in the production of electricity is derived in the dispatching module.

The capacity planning module establishes and annually modifies the state's utility construction schedule. As in the real world, construction of new plants is stimulated or deferred by evolving discrepancies between old demand forecasts (the basis for current construction programs) and newly revised forecasts based on the previous year's actual demand. The costs of construction are used as inputs in the finance module. The mix of generating technologies, plant retirement dates, and fuel conversion schedules are specified by the modeler in the state-level AUSM.

The pollution control technology module uses a set of simple economic models to estimate the total capital cost and annual revenue requirements of pollution control. The models simulate several currently available systems for control of sulfur dioxide, nitrogen oxides, and particulates at coal-fired power plants. The models are sensitive to key coal, plant, economic, and regulatory parameters that affect capital and operating costs. They were developed by applying engineering analysis and statistical regression techniques to simplify and systematize the costs predicted by other detailed studies and models of major pollution control system components. The capital 
costs for pollution control are passed to the finance module. The pollution control technology module also selects the fuel to be used by the individual generating units to meet emissions requirements. These fuel choices and pollution control operating costs are passed to the dispatching module for the state-level AUSM.

The dispatching module allocates the quantity of electricity that is calculated in the demand module among generators designed to meet the demand. A linear programing model is used to estimate either 1) the least cost energy allocation subject to constraints on the amounts of various emissions or 2) the allocation that produces the fewest emissions of a selected pollutant while constraints are maintained on operating costs and other pollutants. In the state-level AUSM the dispatching module operates within a single-region single-period context and fuel choice is determined by the pollution control technology module. Once the dispatching module has obtained a solution, operating costs are passed to the finance module.

The finance module computes a total revenue requirement for the electric utilities in a state by utilizing base-year and historical plant data, actual revenues for the current year from the demand module, new construction costs from the planning module, pollution control costs (both capital and operating) from the pollution control technology module, and generating operating costs from the dispatching module. The current year's revenue requirement goes to the rate rescheduling component of the demand module where it helps determine the following year's demand and actual revenues.

Delivered coal prices are calculated by the coal supply module. These prices, along with the prices of other primary fuels such as oil and natural gas, are supplied to the AUSM's core modules before simulation begins. Thus, the coal supply module is a separate component that is solved first at the national level by iterating with a multi-state, multi-period module, which computes electricity prices as a function of the coal prices calculated by the coal supply module. The electricity prices, at power pool levels, in turn yield new demands for electricity and, hence, coal. The new coal demands yield new coal prices from the coal module. Coal prices are estimated for 30 years beyond the AUSM horizon so the model can take them into account when selecting coals for new power plants. Using the results of this iterative 
process for each year of the planning horizon ensures that the effects of coal depletion are reflected in the prices seen by each state.

The coal supply module simulates the costs of mining, preparing, and transporting coal to compute least-cost delivered coal prices for each demand region. Coal originates from 35 simulated coal supply regions in 24 states. The coal supply regions were defined by disaggregating U.S. Bureau of Mines (BOM) districts wherever they were split by state lines. This allows the AUSM's results to be expressed by state of by BOM district. Coals are classified into coal-types based on 11 sulfur dioxide and three higher heating value categories.

A number of options can be used to simulate mining costs in the coal supply module. One option is to use the econometric forecasts developed for the U.S. Department of Agriculture by Green and Michelson. (a) These forecasts cover the period for 1980 through 1990 and are based on actual coal prices reported for over 76,000 shipments between 1973 and 1980 . For periods beyond 1990, escalation rates are specified by the user. Another option employs engineering-based mine cost equations together with data on the quality and distribution of coal reserves in each supply region and assumptions regarding the size of the mines that would exploit these reserves. The first mine cost equations(b) used by the AUSM were developed by MCLean Research Center, Incorporated (MRCI) for the Energy Information Administration (EIA), U.S. Department of Energy. These equations were included in the EIA's Resource Allocation and Mine Costing (RAMC) model. These equations have since been revised by Science Applications International Corporation (see U.S. Department of Energy. Energy Information Administration, 1987).

Using the RAMC model's mine costing methodology, the coal supply module first computes four components of the minemouth cost of coal: initial capital, deferred capital, labor productivity, and power and supplies. These components

(a) Green, John W. and Ari M. Michelson. 1983. Coal Price Forecast Equations: Forecast Equations, Interpretation, and Application. Draft. Department of Economics, Colorado State University.

(b) MCLean Research Center, Inc. 1983. Development of Underaround Mine Cost Estimating Equations, and MCLean Research Center, Inc. 1983. Development of Surface Mine Cost Estimating Equations. 
are expressed as functions of mine size, seam thickness, seam depth, or overburden ratio. The cost equations characterize nine types of "model mines" --four underground and five surface--by geographic region. The underground model mines, for example, simulate mines in Southern and Northern Appalachia, the Midwest, and the Far West. The surface model mines simulate mines in 1) Central and Northern Appalachia, 2) the Midwest, 3) the Far West (except Campbell County, Wyoming), and 4) Campbell County, Wyoming. The minimum total minemouth cost of coal for a specific mine is obtained by sumning the costs (in present value terms) of the four components. Next, for each coal-type, the mine having the lowest present value cost (normalized by mine size) is identified for the region. (a)

Once minemouth costs have been computed, coal preparation and transportation costs are calculated. A detailed coal preparation model also is incorporated in the AUSM's coal supply module. Coal preparation involves crushing, screening, or cleaning. Most bituminous coals are crushed and screened. The objective of the coal cleaning process is to improve the value of the coal delivered to plants by reducing the presence of impurities such as ash, sulfur, and moisture. Cleaning is obtainable only at the cost of constructing and operating cleaning plants and the cost of combustible material that is discarded along with the refuse from the cleaning process. The cleaning component of the coal preparation model is based on coal washability data collected and maintained by the BOM.

The final component in the coal supply module is a set of coal transportation costs linking each of the supply regions to the 48 demand regions. These origin-destination costs are computed for rail-water and railonly routings using the U.S. Department of Agriculture's Transportation Analys is System (TAS). The TAS is incorporated into the coal supply module in a manner that allows analysts to determine how transportation changes may affect future coal movements and prices.

(a) In the state-level AUSM, the effects of depletion are ignored so only the set of least-cost mines is considered within the region. The national-level AUSM, however, will capture depletion effects by rank ordering mines within coal-types. 
Once coal mining, preparation, and transportation costs are delineated, the coal supply module determines the delivered cost of various types of coal for each demand region. The delivered cost of coal as the sum of minemouth, preparation, and transportation costs. Only the least-cost delivered price for any one coal-type is assigned to a given demand region. The algorithm which generates the least-cost delivered prices also takes coal-type changes due to preparation into account. For example, cleaning a raw coal-type often results in a delivered coal-type with a lower sulfur content. The coal supply module provides least-cost coal prices to the demand regions in terms of delivered coal-types.

\subsection{COAL MINING EMPLOYMENT: ESTIMATES AND IMPACTS}

Energy, employment, and other economic impacts of various scenarios are determined by the national-level AUSM's energy and employment impacts module (EEIM). In general, the objective of the EEIM is to determine the direct and indirect impacts of alternative electricity policies on the use of primary fuels, on employment, and on air pollution. There are two major objectives of the EEIM with regard to employment impacts 1) to calculate, at the statelevel, the direct employment effects in coal mining, coal transportation, and electric utility industries, and 2) to calculate, at the national-level, both the direct and indirect employment effects that would result from the implementation of various policies. Estimates of direct and indirect employment effects at the national level are obtained using input-output (1/0) analysis. The I/0 analysis is supported by a data base maintained by the Energy Resource Group (ERG) at the University of Illinois at Urbana-Champaign. Various technical coeffecients and conversion factors from this ERG data base are combined with AUSM results to estimate these effects. For a description of the theoretical and technical aspects of using I/0 analysis in this manner, see Appendix A: Input/Output Analysis and Employment Effects.

The EEIM methodology for deriving national level effects can be sumarized as follows. First, baseline projections of final consumption and technology are developed. The baseline projections of final consumption are derived by combining estimates of commodity final demand from the U.S. Bureau of Labor Statistics (BLS) with energy consumption and capital results of a baseline 
AUSM scenario. Baseline projections of technology are derived by combining ERG data with electric sector fuel use and sales results from the baseline AUSM scenario.

Second, labor multipliers or "intensities" are calculated by combining BLS data on occupation-industry labor requirements with technical coefficients that define the projected technology (Hannon, et al. 1981). These labor intensities convert final consumption (measured in British thermal units or dollars) into direct and indirect employment (measured in fuel-time equivalents for 40 occupations) for the baseline case.

Third, the results of AUSM scenarios that simulate aiternative energy policies are used to define alternative projections of final consumption, technology, and employment. The difference between the alternative employment projections and the baseline employment projections constitutes the direct and indirect employment effects. These employment effects are presented in the aggregate. No attempt, for example, is made to separate the direct form the indirect employment effects or to distinguish the employment effects caused by production changes in specific industries. Also, no attempt is made to delineate induced effects.

Direct coal mining employment effects at the state level are derived using Bechtel data on coal production (Champagne 1982). Four coal mine-types are delineated in the Bechtel data: eastern undergound, eastern surface, western underground, and western surface. Coal production for these four mine-types is assumed to be 2, 4, 2, and 6 million tons per year, respectively. Estimates of direct coal mining employment effects within the state are obtained by combining these Bechtel data with the AUSM's estimates of the state's coal production. These direct employment effects are measured in full-time equivalents for the same 40 occupations that are used for the national level employment effects. Analogous procedures also are used to obtain direct employment effects for the state's coal transportation industry as well as for the construction, operating, and maintenance sectors of the state's electric utilities industry. These effects are totaled to provide the total direct employment effect for the state. 


\subsection{EVALUATION}

The major strength of the AUSM, like that of the CEUM, is its ability to generate direct coal mining employment effects at the local, i.e. coal supply region, level. This strength arises from the AUSM's coal supply module's ability to use mine costing models similar to those utilized by the CEUM. Because the AUSM's coal supply regions are smaller than states, the geographic units of measure are groups of counties. Also, because these mine costing procedures provide a direct link between coal production and coal mining employment, local differences in coal mining conditions could be taken into account. The major weakness of the AUSM, however, is that this ability ignored.

At the state level, the mine costing procedures in the coal supply module are used only to determine the minimum prices of various coal types. These prices are then used by the AUSM's core modules, i.e. the demand module and the pollution control technology or dispatching modules, to estimate coal production by state rather than by coal supply region. These state-level coal production estimates, in turn, are converted to direct state-level employment effects using the national-level EEIM's general purpose algorithm, a relatively crude algorithm that is totally unlike the algorithms linking labor productivity with coal production in the coal supply module. In this process, both consistency and the ability to characterize local direct impacts are lost.

Another major strength of the AUSM is the way the electric utility sector is modeled. The quantities of electricity demanded, for example, are directly sensitive to both the price of electricity as well as the prices of competing fuels. The quantities of electricity supplied are also sensitive to fuel prices in the long run. This price sensitivity of supply is inherent in the methods used to simulate planning for and construction of new generating capacity. Using the state as the basic geographic unit for electricity supply also makes it easy to account for a state's tax and regulatory policies.

The consumption of electricity and other primary fuels such as coal in the non-utility sectors, i.e. residential, commercial, industrial, and transportation, is also directly sensitive to current prices. On the other hand, the estimates of coal consumption are aggregates, which, unlike those 
provided by the CEUM, do not distinguish coal consumption by specific end uses such as coking, synthetic fuels, or export. Also, consumption of coal in the non-utility sectors is assumed to occur only in the industrial sector.

The AUSM's coal production estimates, like the CEUM's coal production estimates, may be systematically biased. The bias is introduced on the coal demand side of the model. This demand side bias is caused by ignoring regional population changes that pollution control policies might induce. An air pollution control policy that allows extensive switching from high-sulfur to low-sulfur coal, for example, would probably induce population declines in high-sulfur coal regions and population increases in low-sulfur coal regions. To the extent that high-sulfur coal deposits are located in some states, while low-sulfur coal deposits are located in other states, some state's populations will decline whereas other state's populations will increase. These population changes would, in turn, affect the demand for electricity and other primary fuels in these states. To simulate the full effects of a pollution control policy of this type, these population and demand changes should be taken into account.

This migration problem might be resolved, however, because the AUSM has the potential for incorporating policy-induced immigration and emigration into analyses. The demand equations in the AUSM's demand module are formulated in terms of per capita demand. Total demand is derived by multiplying the estimates of per capita demand by estimates of population. If population changes induced by a pollution control scenario were known, then the population estimates used by the demand module could be modified accordingly. Because these scenario-induced population changes can only be estimated after the policy is simulated, an iterative process would have to be used. 



\subsection{ARTHUR D. LITTLE, INC.'S CONSOLIDATION COAL STUDY}

The methodology presented in this section was developed by Arthur $D$. Little, Inc. (ADL) in response to a request by Consolidation Coal Company. The resulting study (Arthur D. Little, Inc. 1985), examines the total economic consequences of two hypothetical air pollution control scenarios. These consequences include the compliance cost to the utility industry, the impacts on those industries directly affected by utility decisions, and the community adjustment costs associated with regional shifts in economic activity. ADL conducted the study in conjunction with Energy Ventures Analysis, Inc. (EVA), who provided ADL with estimates of the changes in coal production induced by the pollution control scenarios.

Because the model used to derive the coal production estimates were not described in the documentation at our disposal, this chapter is divided into only two sections. Section 5.1 contains an outline of the methods used by $A D L$ to derive employment effects induced by the changes in coal production supplied by EVA. A short summary of EVA'a estimation procedures is also presented in this section. In section 5.2, the methods used to estimate the employment effects are briefly evaluated. The materials used as sources of information include Arthur D. Little, Inc. (1985), Jonash (1985), and telephone conversations with Ronald S. Jonash, Vice President of ADL's Development, Economics and Management Group.

\subsection{COAL MINING EMPLOYMENT: ESTIMATES AND IMPACTS}

The methodology used by EVA in estimating coal production changes employed powerplant-specific analyses of the costs of reducing $\mathrm{SO}^{2}$ emissions. Both the costs of retrofitting powerplants with flue gas desulfurization systems ("scubbers") and the costs of alternative coals (transportation plus minemouth costs) were used in calculating the cost-effectiveness of emissions reduction at each major coal-fired powerplant. The emissions reduction decisions were optimized by utility system to achieve the lowest cost solution. EVA forecasted equilibrium coal prices at various production levels to determine the costs of coal switching. The individual utility decisions were aggregated to determine total regional coal production shifts. This approach has been 
used subsequently by the Electric Power Research Institute in analyzing the impacts of emissions reductions in other coal markets.

Direct coal mining employment effects were estimated by combining the coal production changes provided by EVA with 1982 data on labor productivity in the coal mining industry. The labor productivity data were obtained from the U.S. Mine Safety and Health Administration and differentiate labor productivity by state and mine-type, i.e. deep or surface. Estimates of direct employment effects in the coal mining industry were derived for each coal producing state. State-level estimates of direct employment effects in the transportation and utility industries also were determined.

Estimates of indirect and induced employment effects were derived for coal mining areas within four major coal producing regions, i.e. Northern Appalachia, Central and Southern Appalachia, the Illinois Basin, and the West. as well as for non-coal mining areas within the coal producing regions and the rest of the United States. To derive these indirect and induced effects, $A D L$ used a method based on input/output (I/0) analysis. This method can be summarized as follows. First, estimates of final demand changes in all support industries, i.e. those industries that directly and indirectly provide goods and services to the coal mining, transportation, and utility industries, were derived. Estimates of final demand changes in support industries of coal mining areas were based on the judgment of coal mining and other industry specialists employed by ADL.

Second, employment multipliers for the support industries were constructed from earnings multipliers and employment-to-earnings ratios. The earnings multipliers were obtained from the Regional Input Output Modeling System (RIMS II), which is provided by the U.S. Department of Commerce. RIMS II earnings multipliers capture both indirect and induced effects of per unit, final demand changes (Cartwright, Beemiller, and Gastely 1981, and Appendix A: Input/0utput Analysis and Employment Effects). The employment-to-earnings ratios were obtained from the National Planning Association. Indirect and induced employment changes were estimated by multiplying the final demand changes in the supporting industries by the appropriate sectoral employment multiplier.

The indirect and induced employment effects, once calculated, are distributed to the coal mining areas within the coal producing regions 
according to a set of allocation rules. The allocation of indirect and induced employment effects in the construction, transportation, communication, utility, retail, and service industries, for example, was proportional to coal mining employment. The allocation of indirect and induced employment effects in the agriculture, mining, manufacturing, wholesale, financial, insurance, and real estate industries was proportional to employment in those industries.

The allocation rules also accounted for differences in what the economic growth of local communities would have been in the absence on pollution control policies. Communities suffering a decline in economic opportunities, for example, would be more likely to incur job losses than growing communities. Thus, a greater proportion of the negative indirect and induced employment effects were allocated to these coal mining areas than to stable or growing coal mining areas.

Demand changes in support industries outside the coal producing areas were estimated by multiplying the final demand changes developed for the support industries within the coal producing areas by "import coefficients". These import coefficients were derived by subtracting regional RIMS II coefficients from national RIMS II coefficients. The difference between the two sets of coefficients represents the proportion of industry inputs imported to the coal producing region from surrounding states and from the rest of the U.S. Indirect and induced employment effects were then estimated by multiplying the demand changes by the appropriate sectoral earnings multipliers.

\subsection{EVALUATION}

ADL's methodology shows that reasonable estimates of indirect and induced employment effects can be obtained at the state and local level. The methods used to allocate these effects at the local level, however, could be refined to more fully account for local differences. The reliability of ADL's employment estimates, however, is uncertain. First, important details about the methods used by EVA to estimate changes in coal production are not readity available. Second, the methods used by ADL to determine the final demand changes in those industries that directly and indirectly provide goods and services to the coal mining industry are not fully documented. Problems in either of those procedures could critically affect the final results. 


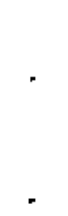




\subsection{PROPOSED FUTURE RESEARCH}

The evaluations in the preceding sections indicate that current models such as the CEUM and the AUSM have the ability to provide reasonable local estimates of direct coal mining employment effects that policy induced changes in coal production might cause. Neither the CEUM nor the AUSM, however, provide estimates of indirect or induced employment effects at the state or local levels. The ADL study provides state and local estimates of indirect and induced employment effects caused by changes in coal production that are appropriate.

The estimates of direct coal mining employment effects generated by the CEUM and the AUSM may not be without problems. Neither model, for example, accounts for policy-induced population changes when simulating air pollution control scenarios. In addition, the CEUM's estimates of direct employment effects in the coal supply regions may be systematically biased because the demand for electricity in the utility sector is not sensitive to electricity prices. Also, the AUSM's estimates of direct employment effects are pertinent at the state level rather than at the coal supply region level. These estimates are not consistent with the procedures used to derive coal supply prices used in the AUSM's core modules either. The magnitude of these problems is not known.

In addition to those discussed in this report, alternative conversion factors exist which also can be used to calculate direct coal mining employment effects from the coal production estimates generated by national models. In a Congressional Budget Office study (1986), for example, employment estimates are derived in a separate model which converts CEUM-generated tons of coal mined per year in each supply region into labor requirements, i.e. labor years, by applying an appropriate multiplier for each region based on 1983 average productivity. An Office of Technology Assessment study (1984) uses a similar approach but at the state level and with a range of productivities.

The purpose of this section is to outline several research topics that would provide the EPA with (1) more information with which to evaluate the CEUM and AUSM's estimates of direct employment effects, and (2) estimates of 
indirect and induced employment effects at the local, i.e. coal supply region, level.

\subsection{SENSITIVITY ANALYSIS OF THE CEUM AND AUSM'S COAL PRODUCTION ESTIMATES}

The purpose of this research is to determine the importance of the potential modeling problems indicated by this review. These problems include the inability of the CEUM and the AUSM to simulate policy-induced population changes, the price insensitivity of electricity demand in the CEUM, and the inconsistency between algorithms linking labor productivity with coal production in the AUSM's coal supply module and algorithms linking coal production with direct employment effects in the AUSM's energy and employment module. The magnitude of these potential problems would be determined by sensitivity analysis. For example, in various scenarios the population estimates used by the AUSM's demand module would be increased or decreased, by say, 10 percent. The results of these scenarios would be compared with the results of a base case. If the differences between the base case and scenario results are small, then the population change problem may not be very important. Other sensitivity analyses would include 1) a comparison of the CEUM's base case results with the results of "paired" pollution control scenarios--one scenario run normally, the other scenario run iteratively--to determine the importance of the CEUM's demand inflexibility, and 2) a comparison of the direct coal mining employment results obtained by using the AUSM's EEIM with the employment results that would have been obtained if the conversion factors in the AUSM's coal supply module were used.

\subsection{ESTIMATING STATE-LEVEL EMPLOYMENT EFFECTS CAUSED BY CHANGES IN COAL PRODUCTION}

The purpose of this research is to determine how various hypothetical air pollution control policies implemented at the state level would change the level of employment in the state's coal mining industry and how these changes, in turn, would affect employment in other sectors of the state's economy. This information could be used by the states and EPA to compare the employment impacts of various ways of meeting air pollution standards. 
The first step in this research would be to select a specific state. Criteria for selection might include 1) the availability of models that can be used to determine the indirect employment effects caused by changes in coal production within the state's coal mining regions, and 2) both highsulfur and low-sulfur coal supply regions within the state. The second step would be to develop several hypothetical air pollution control policies that the state might implement and to use the AUSM or CEUM to estimate the direct employment effects of coal production changes that these hypothetical policies might cause. The third step would be to estimate the indirect employment effects of coal production changes by using the model(s) obtained in step one. In the fourth step, the estimates of the total employment effects of coal production changes would be obtained. The induced effects would be obtained by combining the direct and indirect employment effects obtained in steps two and three with a regional economic model such as PNL's Metropolitan and State Economic Region (MASTER) model. The fifth step would be to compare the results of the various hypothetical air pollution control scenarios.

\subsection{DESCRIPTION AND EVALUATION OF METHODS USED TO DETERMINE EMPLOYMENT EFFECTS CAUSED BY OUTPUT CHANGES IN THE TRANSPORTATION AND ELECTRIC UTILITY INDUSTRIES}

The purpose of this research is to review the CEUM, AUSM and ADL's methods used to estimate employment impacts in the transportation and electric utility industries that air pollution control policies might induce. For example, increased manufacture and use of pollution control equipment such as scrubbers would result from most pollution control policies. The review would include:

1. descriptions of how the models link air pollution control policies to changes in the output of the transportation and electric utility industries;

2. descriptions of how the models estimate the direct, indirect, and induced employment effects that are caused by output changes in these industries, and

3. evaluations of the linkages and estimates described. 


\subsection{ESTIMATING THE TOTAL STATE-LEVEL IMPACTS CAUSED BY CHANGES IN COAL PRODUCTION}

The purpose of this research is to determine through case studies how changes in total employment caused by changes in coal production might affect the population, income, and infrastructure of coal mining communities. This research, which represents and extension of topic 6.2 above, is important to verify the accuracy of the model estimates. The first step in this research would be to assemble information on the economic, demographic, housing, land use, public sector, social organization and well-being characteristics of the coal producing regions in the state. Data will be obtained from regional development comnissions, the United Mine Workers, coal industry representatives, and local government officials as well as from traditional sources such as labor market employment statistics published by state and federal governments. The second step would be to describe how changes in total employment affect 1) other segments of the local economy, 2) enigration or immigration rates, 3) the local standard of living, and 4) the provision of public services.

\subsection{ASSESSING ALTERNATIVE COAL MINER COMPENSATION POLICIES.}

The purpose of this research is to assess various policies that might be used to mitigate the effects of acid rain policies on coal mining unemployment. The alternative policies would be identified in the first phase of this research. Alternatives might include lump sum payments to coal miners, retraining programs and/or relocation programs, tax incentives, targeted federa] job programs. These alternatives will be assessed in terms of impacts on coal miner welfare, employment and migration, costs to the federal government and political obstacles and other criteria important to EPA. 


\section{REFERENCES}

Arthur D. Little, Inc. 1985. Economic Impacts of Alternative Acid Rain Control Strategies: Final Report to Consolidation Coal Company. Cambridge, Maryland.

Cartwright, J. V., R. M. Beemiller, and R. D. Gustely. 1981. RIMSII Regional Input-0utput Modeling System: Estimation, Evaluation, and Application of a Disaggregated Regional Impact Model. U.S. Government Printing Office, Washington, D.C.

Champagne, P. 1982. The Maintenance, Operation Vectors, and Construction Matrices of the Bechtel Eneray Industries with Special Energy Calculations on Pollution Control Technologies. (ERG Document 319), Energy Research Group, University of Illinois at Urbana-Champaign, Urbana, Illinois.

Hannon, B., R. A. Herendeen, and T. Blazeck. 1981. Eneray and Labor Intensities for 1972. (ERG Document 307), Energy Research Group, University of Illinois at Urbana-Champaign, Urbana, Illinois.

ICF Incorporated. 1985. An Economic Assessment of Long-Term Emission Reduction Alternatives. Washington, D.C.

ICF Incorporated. 1986. Analys is of 6 and 8 Million Ton and 30 Year/NSPS and 30 Year 1.2 Lb. Sulfur Dioxide Emission Reduction Cases. Washington, D.C.

ICF 1ncorporated. 1985. Analysis of Sulfur Dioxide and Nitrogen Oxide Emission Reduction Alternatives with Electricity Rate Subsidies. Washington, D.C.

Jonash, R. S. 1985. "Response to Lester Lave: Economic Impacts of Alternative Acid Rain Control Strategies." In Acid Rain: Economic Assessment. Proceedings of a Conference on Acid Rain. ed. P. Mandelbaum, (Environmental Science Research, v. 33). Plenum Press, New York.

Stauffer, C. H., Jr. 1985. "Cost and Coal Market Effects of Alternative Approaches for Reducing Electricity Utility Sulfur Dioxide Emissions." In Acid Rain: Economic Assessment. Proceedings of a Conference on Acid Rain, ed. P. Mandelbaum. (Environmental Science Research v. 33). Plenum Press, New York.

U.S. Congressional Budget Office. 1986. Curbing Acid Rain: Cost, Budget, and Coal-Market Effects. U.S. Government Printing Office, Washington, D.C.

U.S. Department of Energy. Energy Information Administration. 1987. Documentation of the Resource Allocation and Mine Costing (RAMC) Model: (Methodology Description). (DOE/EIA-M021), U.S. Government Printing Office, Washington, D.C. 
U.S. Office of Technology Assessment. 1984. Acid Rain and Transported Air Pollutants: Implication for Public Policy. (0TA-0-204), U.S. Government Printing office, Washington, D.C. 


\section{APPENDIX A}

INPUT/OUTPUT ANALYSIS AND EMPLOYMENT EFFECTS 
APPENDIX

\section{INPUT/OUTPUT ANALYSIS AND EMPLOYMENT EFFECTS}

In its simplest form, an I/O table can be thought of as a matrix, $A$, in which each element, $i . e . a_{i j}$, represents the amount of the $i$ th sector's output required to produce one unit of the $j$ th sector's output. As such, the A matrix represents the technical input requirements for production on a per unit output basis. The elements of the A matrix are called "technical coefficients". Technical coefficients are usually derived from sales data so that the units of measurement are dollar/dollar. If we let $X$ denote a vector of gross output and $Y$ denote a vector of final demand, then we can derive the following relationship:

$$
X-A X=Y
$$

Restated, gross output, $X$, less output used as inputs for intermediate production processes, $A X$, equals output available for final consunption, $Y$. In this demand driven model, the output available for final consumption will equal final demand exactly. The $1 / 0$ modeling framework requires four major assumptions: 1) constant returns to scale, 2) no input substitutability, 3) equilibrium pricing, and 4) perfectly elastic supply.

As a tool for forecasting, equation (1) is rewritten as

$$
X=(I-A)-I_{Y}
$$

and

$$
X c=(I-A)-1 y c
$$

or, if technical requirements are known to have changed,

$$
X C=\left(I-A^{m}\right)-1 Y m-\left[(I-A)^{-1} Y\right]
$$

The (I - A)-1 matrix in equations (2) and (3) is known as the multiplier matrix and its elements provide both the direct and indirect requirements for producing one unit of final demand by a given sector. Thus, as is shown in equation (3), given changes in final demand, $Y$, one may use the multiplier matrix to predict the direct and indirect impacts on the production of gross 
industrial output. Equation (4) extends the potential analys is by accounting for technological changes that might occur. Thus, given a modified final demand, Ym, and modifications in the technical requirements for production, Am, one can calculated a modified gross industrial output. Subtracting the original gross industrial output from the modified gross industrial output yields the direct and indirect changes in gross industrial output.

Other refinements of the multiplier matrix are also possible. One possible refinement is to convert the multiplier matrix from an industry-based to a commodity-based accounting scheme. Another refinement involves the inclusion of energy requirements in physical units, i.e. Btu's, thus avoiding certain pitfalls of solely dollar-based models. The EEIM uses a commoditybased matrix containing technical coefficients measured in 1) Btu/Btu to describe the relationships among the energy producing sectors, 2) Btu/Dollar to describe the relationships between energy producing sectors and non-energy producing sectors, and 3) Dollar/Dollar to describe the relationships among non-energy producing sectors. Also, by postmultiplying the multiplier matrix and final consumption vector by an appropriate conversion factor matrix, the units of the gross output vector, $X$, can be changed.

Whether or not I/0 multipliers account for indirect and induced effects depends on how the household sector is treated. If the household sector is treated, exogenously, i.e. as part of final demand, then the multipliers obtained from the (I-A) ${ }^{-1}$ matrix account for the direct and indirect effects of change sin final demand. If, however, the household sector is treated endogenously, i.e. as part of the technical coefficients matrix rather than as part of final demand, then the multipliers account for direct, indirect, and induced effects.

An alternative method of obtaining induced effects is to use what are known as earnings multipliers. Earnings multipliers are found in the household row of a multiplier matrix derived from a technical coefficients matrix that includes the household sector. Earnings multipliers show the direct, indirect, and induced earnings impacts caused by per-unit changes in final demand. Like other $1 / 0$ multipliers, conversion factors can be used to change the measurement units of earnings multipliers. 


\section{DISTRIBUTION}

No. of

Copies

OFFSITE

10 DOE/Office of Scientific and Technical Information

C. Bullard, Director Office of Energy Research

901 South Mathews

Urbana, IL 61801

R. Jonash

Arthur D. Little, Inc.

30 Memorial Drive

Cambridge, MA 02141

B. McLean

U.S. Environmental Protection Agency

401 "M" Street, S.W.

Washington, DC 20460

R. Morris

U.S. Department of Energy

1000 Independence Avenue, S.W. Washington, DC 20460

J. Rose

ICF Incorporated

9300 Lee Highway

Fairfax, VA 22031

3 J. Schakenback

U.S. Environmental Protection Agency

401 "M" Street, S.W.

Washington, DC 20460

3 P. Schwengles

U.S. Environmental Protection Agency

401 "M" Street, S.W.

Washington, DC 20460
No. of

Copies

ONSITE

DOE Richland Operations office

J. J. Sutey

23 Pacific Northwest Laboratory

J. M. Callaway

R. C. Darwin (10)

R. J. Nesse (3)

E. J. Stenehjem

Publishing Coordination (2)

Technical Report Files (5) 


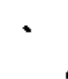

